Gynecologic and

Obstetric Investigation

\title{
Fresh and Frozen-Thawed Embryo Transfer Compared to Natural Conception: Differences in Perinatal Outcome?
}

\author{
Suzanne Spijkers Jan Willem Lens Roel Schats Cornelis B. Lambalk \\ VU University Medical Center, Department of Obstetrics and Gynecology, Division of Reproductive Medicine, \\ Amsterdam, The Netherlands
}

\section{Keywords}

Assisted reproductive technology $\cdot$ In vitro fertilization .

Perinatal outcomes · Freeze-all · Frozen-thawed embryo transfer $\cdot$ Cryopreservation

\section{Abstract \\ Background/Aim: To compare the pregnancy outcome of singletons conceived after transfer of cryopreserved and thawed embryos (frozen embryo transfer [FET]) to singletons conceived after fresh embryo transfer (fresh ET) and natural conceived singletons. Methods: Using a retrospective data analysis on a study population consisting of 1,261 singletons born after FET and 2,519 singletons born after fresh ET be- tween 2006 and 2015. The control group consisted of single- tons born after natural conception. Main outcome measures consisted of birth weight (in grams), gestational age, pre- term birth ( $<37$ weeks of gestation), being large for gesta- tional age (LGA, above 90th weight percentile adjusted for gestational age) and Apgar scores. Results: Babies born after FET had an increased risk of high birth weight (adjusted OR [AOR]) 2.92; 1.503-3.482) and being LGA (AOR fresh ET vs. FET $1.47 ; 1.210-1.787$ ) compared to singletons born after}

\section{KARGER}

E-Mail karger@karger.com www.karger.com/goi

\section{The Author(s) \\ Published by S. Karger AG, Basel \\ Karger \\ Open access}

This article is licensed under the Creative Commons AttributionNonCommercial-NoDerivatives 4.0 International License (CC BYNC-ND) (http://www.karger.com/Services/OpenAccessLicense) Usage and distribution for commercial purposes as well as any distribution of modified material requires written permission. fresh ET, as well as higher birth weights compared to natural conceived children. Conclusions: Singletons born after FET have a higher risk of high birth weight and being LGA compared to singletons after fresh ET and compared to natural conceived singletons. We assume that the freezing process might be the underlying cause.

(c) 2017 The Author(s)

Published by S. Karger AG, Basel

\section{Introduction}

For children born after assisted reproductive technologies (ARTs) in general, their health has been a concern since the first successful treatments. Several studies have shown a higher occurrence of low birth weight (LBW, $<2,500 \mathrm{~g})$, very LBW $(<1,500 \mathrm{~g})$ and preterm birth in children conceived through ART [1-8]. Other studies have concluded that children conceived through ART do not have increased risks of adverse perinatal outcome [9-12]. However, a recent systematic review of 45 cohort studies showed that neonates born after ART compared to those who were naturally conceived have a higher risk of birth defects [3]. Not clear is whether this higher risk of adverse

Suzanne Spijkers, BSc

VU University Medical Center

Devision of Reproductive Medicine

De Boelelaan 1118, 1081 HZ Amsterdam (The Netherlands)

E-Mail suzannespijkers@outlook.com 
outcomes is resulting from the ART procedure itself, the underlying sub- or infertility or other causes [13]. Also the long-term health of children born after ART is a matter of concern since studies suggest that these children might be at increased risk for metabolic and cardiac diseases [14-17].

Since the birth of the first baby born after frozen embryo transfer (FET) in 1984 [18], this technique has become increasingly important worldwide. In 2004, up to $30 \%$ of the children born after ART were from cryopreserved embryos [19]. These numbers are increasing worldwide not only because of satisfactory pregnancy and live birth rates after cryopreservation $[20,21]$ but also because elective single embryo transfer (eSET) is now in favour over double embryo transfer (DET) since pregnancy rates and outcomes seem comparable with DET. Also, the occurrence of less multiple pregnancies after eSET compared to DET contributes to the preference for eSET [22]. This trend leaves more embryos available for freezing per cycle to be thawed in later cycles.

The knowledge concerning the differences in obstetrical and neonatal outcome between cryopreserved and fresh embryos is increasing. Literature suggests that the health of neonates born after FET is similar or even more favorable compared to the health of children born after fresh embryo transfer (fresh ET) [23, 24]. Recent studies showed that neonates born after FET have decreased risks of preterm birth, LBW and being small for gestational age (SGA, below 10th percentile) compared to fresh ET [2328]. An increased risk of high birth weight and being large for gestational age (LGA, above 90th percentile) was reported as well [23-29]. A higher risk of congenital malformations for infants born after cryopreservation compared to fresh ET is also described [30,31]. When comparing children born after FET with natural conception, an increased risk for preterm birth, LBW, very LBW and need for caesarean sections was found [6]. These findings imply the need for more research into the underlying cause, especially since the intention to start a freeze-all policy, where all embryos are first cryopreserved and embryo transfer is performed in another menstrual cycle, is upcoming [32].

In this study, our aim was to investigate whether there is an increased risk for being LGA in babies born after cryopreservation in our IVF center and to find factors, which are possible underlying causes. Children born after natural conception, without fertility treatment, were used as a control population. Birth weight, gestational age, weight percentile adjusted for gestational age and Apgar scores are our main outcome measures.

Frozen-Thawed ET and Perinatal Outcome

\section{Materials and Methods}

\section{Data Collection}

Data were collected from the "Electronic Patient Dossier" of the IVF center (study population) and the department of obstetrics and gynecology (control group) of the VU University Medical Center Amsterdam (VUmc). Children born between 2006 and 2015 were included. In order to ensure anonymity of both mother and child, the database was depersonalized; therefore, our study did not involve human subjects. We received confirmation from the Medical Ethics Review Committee of the VUmc that the Medical Research Involving Human Subjects Act (WMO) does not apply to this study and that an official Institutional Review Board approval is not required.

\section{Patient Population}

This study included singleton babies born through IVF/ICSI after at least 24 weeks of gestation (Dutch treatment limit for early preterm births [33]) in the IVF center. Babies born after single embryo transfer as well as DET were included. Excluded were all vanishing twins [34], defined as a singleton birth where a twin pregnancy was recorded at 7 weeks of gestational age (double heartrate at ultrasound). Gestational surrogates and donor oocyte pregnancies were excluded as well. As a reference group, we included babies born in the VUmc after natural conception (no fertility treatment).

\section{Outcome Measurements}

For the maternal background characteristics, the following variables were included: age at the time of birth, parity, cause of infertility and number of embryos transferred (SET or DET). The perinatal outcome measurements used were birth weight (in grams), LBW (<2,500 g), high birth weight ( $>4,500 \mathrm{~g})$, SGA (below 10th weight percentile adjusted for gestational age), LGA (above 90th weight percentile adjusted for gestational age), gestational age (days), preterm birth (delivery before 37 weeks of gestation), early preterm birth (delivery before 32 weeks of gestation), Apgar scores (below or above score 7 at $5 \mathrm{~min}$ after birth) and perinatal mortality (deaths occurring before, during or within the first week after birth).

\section{ART Procedures}

Preservation, embryo transfer and stimulation procedures in the laboratory were unaltered during the years of inclusion. A switch in culture medium in January 2009 (from human tubal fluid, HTF, to Sage ${ }^{\circledR}$ ) was shown to have no effect on perinatal outcome [35]. The stimulation, laboratory, embryo transfer and cryopreservation protocols were as described previously [36].

During the last week of receiving an oral contraceptive, women underwent controlled ovarian hyperstimulation with a long $\mathrm{GnRH}$ agonist protocol. Oocyte retrieval was performed $36 \mathrm{~h}$ after administration of human chorionic gonadotrophin (hCG) when there was at least one follicle $\geq 18 \mathrm{~mm}$ and 3 or more follicles $\geq 16 \mathrm{~mm}$. On the day of oocytes retrieval, IVF or ICSI procedures were performed following routine insemination procedures. Fertilization was checked $16-18 \mathrm{~h}$ after insemination. The embryos were incubated under atmospheric $\mathrm{O}_{2}$ concentration, $5 \% \mathrm{CO}_{2}$ and at $37^{\circ} \mathrm{C}$. In fresh cycles, embryo selection and transfer were performed 5 days after hCG administration (3 days after oocytes retrieval).

Gynecol Obstet Invest 2017;82:538-546 539 
Table 1. Maternal background characteristics and perinatal outcome characteristics

\begin{tabular}{|c|c|c|c|c|}
\hline \multicolumn{5}{|l|}{ Maternal background characteristics } \\
\hline Maternal age at time of birth, mean \pm SD & $35.5 \pm 4.0$ & $34.5 \pm 4.3$ & $<0.001$ & $0(0.0)$ \\
\hline \multicolumn{5}{|l|}{ Parity*, $n(\%)$} \\
\hline Multiparae & $573(45.6)$ & $707(28.7)$ & & \\
\hline SET & $1,069(84.8)$ & $1,956(81.7)$ & & \\
\hline DET & $191(15.2)$ & $439(18.3)$ & 0.017 & $125(3.3)$ \\
\hline \multicolumn{5}{|l|}{ Day of embryo transfer**, $n(\%)$} \\
\hline Day 5 & 0 & $2,519(100)$ & & \\
\hline Day 6 & $1,261(100)$ & 0 & & $0(0.0)$ \\
\hline \multicolumn{5}{|l|}{ Cause of infertility, $n(\%)$} \\
\hline Other & $318(25.2)$ & $773(30.6)$ & & \\
\hline Multiple causes & $112(8.9)$ & $261(10.3)$ & & $0(0.0)$ \\
\hline \multicolumn{5}{|l|}{ Perinatal outcome characteristics } \\
\hline \multicolumn{5}{|l|}{ Gender*, $n(\%)$} \\
\hline Male & $637(50.5)$ & $1,277(50.7)$ & & \\
\hline Female & $624(49.5)$ & $1,242(49.3)$ & 0.918 & $0(0.0)$ \\
\hline Gestational age, days, mean \pm SD & $276.1 \pm 13.2$ & $274.7 \pm 14.8$ & 0.004 & $0(0.0)$ \\
\hline \multicolumn{5}{|l|}{ Preterm delivery, weeks, $n(\%)$} \\
\hline $24-37$ & $83(6.6)$ & $188(7.4)$ & 0.349 & \\
\hline $24-32$ & $12(0.9)$ & $44(1.7)$ & 0.063 & $0(0.0)$ \\
\hline Perinatal mortality $* * * *$ & $7(0.6)$ & $20(0.8)$ & 0.540 & $39(1.0)$ \\
\hline
\end{tabular}

FET, frozen embryo transfer; fresh ET, fresh embryo transfer. * Except unknown values. ** All fresh transfers were performed on day 5 after hCG administration (day 3 after oocyte retrieval), cryopreserved embryos were transferred on day 6 after hCG administration. ${ }^{* * *}$ Before, during or after birth, after at least 24 weeks of gestation. Bold values represent significant results $(p<0.05)$.

For frozen-thawed embryos, selection and transfer took place at 20-24 h after thawing.

Cryopreservation of embryos left over after fresh transfer was performed 6 days after hCG administration (4th day after oocyte retrieval) by a standard slow freezing protocol. After $10 \mathrm{~min}$ at room temperature, the embryos were cooled at a starting rate of $-2^{\circ} \mathrm{C}$ per minute to $-6^{\circ} \mathrm{C}$, at $-6^{\circ} \mathrm{C}$ manual seeding was performed, after which freezing continued at a rate of $-0.3^{\circ} \mathrm{C}$ per minute to $-40^{\circ} \mathrm{C}$ and last at $-20^{\circ} \mathrm{C}$ per minute to $-196.0^{\circ} \mathrm{C}$ to be stored in liquid nitrogen. For this a dimethyl sulphoxide (DMSO) solution was used for cryoprotection. Only embryos with less than $20 \%$ fragmentation and a minimum of 8 cells were selected for freezing. In a series of decreasing DMSO media solutions the embryos were thawed. The average time that the embryos remained frozen was $0.9 \pm 1.1$ years. After thawing, the embryos were assessed and cultured for 20-24 h. The embryos were assessed once again before embryo transfer and selection for transfer occurred if either the embryo was in cleavage stage or a blastocoelic cavity was present. Thawed embryos were transferred predominantly in a natural cycle. Embryo transfer was performed 6 days after the hCG injection.

\section{Statistics}

Analysis of the data was performed using Statistical Package for the Social Sciences (SPSS) version 23.0 for Windows. Both chisquare tests (categorical variables) and Student $t$ tests (continuous variables) were performed for statistical analysis of the crude data. When comparing the FET group with the fresh ET group we adjusted for confounding factors (parity, maternal age, gender of the child, number of embryos transferred and gestational age) by using logistic (categorical outcomes) regression and linear (continuous outcomes) regression analyses. ORs and adjusted ORs (AORs) were calculated. We used a one-to-one propensity score matching to analyze the difference in birth weight comparing children born after transfer of cryopreserved embryos with the reference group and comparing children born after transfer of fresh embryos with the reference group. The set of covariates we used consisted of maternal age, gender of the child, parity, gestational age and maternal diabetes mellitus (both preexistent and gestational). Missing values are addressed in Table 1 and were excluded from calculations. In all statistical analyses, a $p$ value of $<0.05$ was considered statistically significant (2-sided). 
Fig. 1. Flowchart of the study population.

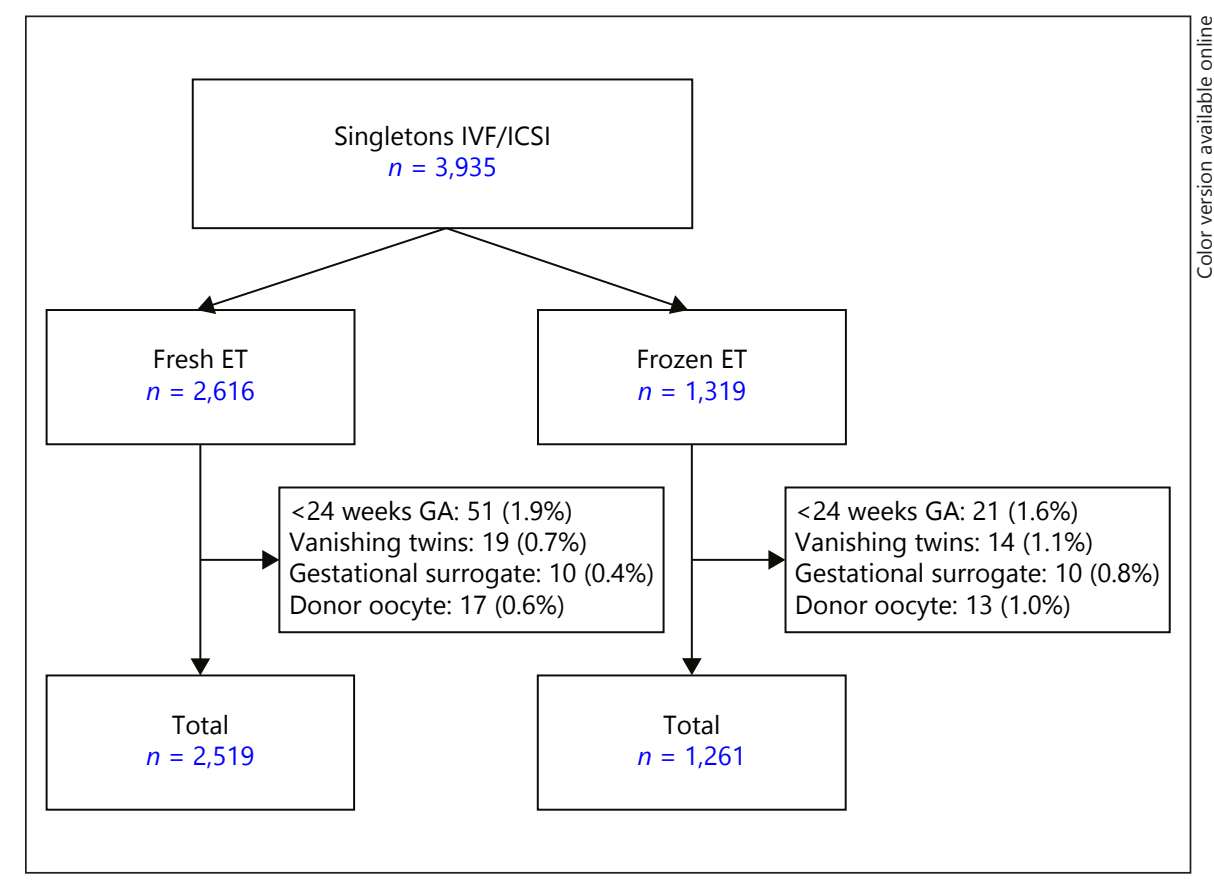

\section{Results}

\section{Characteristics}

In total, 1,261 singletons born after cryopreserved IVF/ICSI and 2,519 singletons born after fresh IVF/ ICSI were compared. Figure 1 shows a flowchart of the study population. Overall, we excluded 72 births before 24 weeks of gestation, 33 vanishing twins, 20 gestational surrogates and 30 pregnancies in which a donor oocyte was fertilized. In Table 1, the maternal background characteristics and child characteristics are shown comparing FET and fresh ET (unadjusted data). Maternal age was higher in the FET group compared to that in the fresh ET group. This difference was statistically significant $(p<0.001)$. The distribution of parity was significantly different, with percentages of primiparae in the frozen-thawed group as $54.4 \%$ compared to $71.3 \%$ in the fresh ET group. In the FET group, $85.8 \%$ were single embryo transfers against $81.7 \%$ in the fresh ET group ( $p=0.017$ ). No significant difference was found in the distribution of gender. Gestational age (in days) in the FET group was higher $(276.1 \pm 13.2)$ than in the fresh ET group $(274.7 \pm 14.8 ; p=0.004)$. Both preterm delivery ( $<37$ weeks of gestation) and early preterm delivery ( $<32$ weeks of gestation) did not differ significantly between fresh ET and transfer of cryopreserved embryos. Also, no significant difference in mortality was found.

Frozen-Thawed ET and Perinatal Outcome

\section{FET Compared to Fresh ET}

Results after performing both linear regression analyses for continuous variables and logistic regression analyses for dichotomous variables between the frozen and the fresh ET group are shown in Table 2. Both analyses were performed with and without adjusting for maternal age, parity, gender of the child and number of embryos transferred. Gestational age differed significantly between the FET group and the fresh ET group before adjusting for confounders (FET $276.1 \pm 13.2$, fresh ET $274.7 \pm 14.8$, $p=0.004)$; after adjusting for confounders this still differed significantly by 1.2 days $(p=0.018)$. The cryopreserved group did not differ significantly from the fresh ET group as regards preterm birth before 37 weeks of gestation. When comparing birth weight as a continuous variable, the FET group showed a statistically higher mean birth weight compared to the fresh ET group $(3,512 \pm 589$ $\mathrm{g}$ for the FET group, 3,368 $\pm 616 \mathrm{~g}$ for the fresh ET group, $p$ value $<0.001)$. After adjusting for confounders, this difference was still significant $(p<0.001)$. A significant difference can also be seen in LBW $(<2,500 \mathrm{~g})$ where the FET group has a lower risk compared to the fresh ET group (AOR $0.62 ; 0.389-0.975 ; p=0.039$ ) and in high birth weight $(>4,500 \mathrm{~g})$ where the frozen-thawed group had a higher risk than the fresh ET group (AOR 2.06; 1.320$3.221 ; p=0.001$ ). The FET group showed a lower risk for a percentile score below 10 (AOR 0.60; $0.450-0.811 ; p=$ 0.001 ) and a higher risk for a percentile score above 90 
Table 2. FET compared to fresh ET

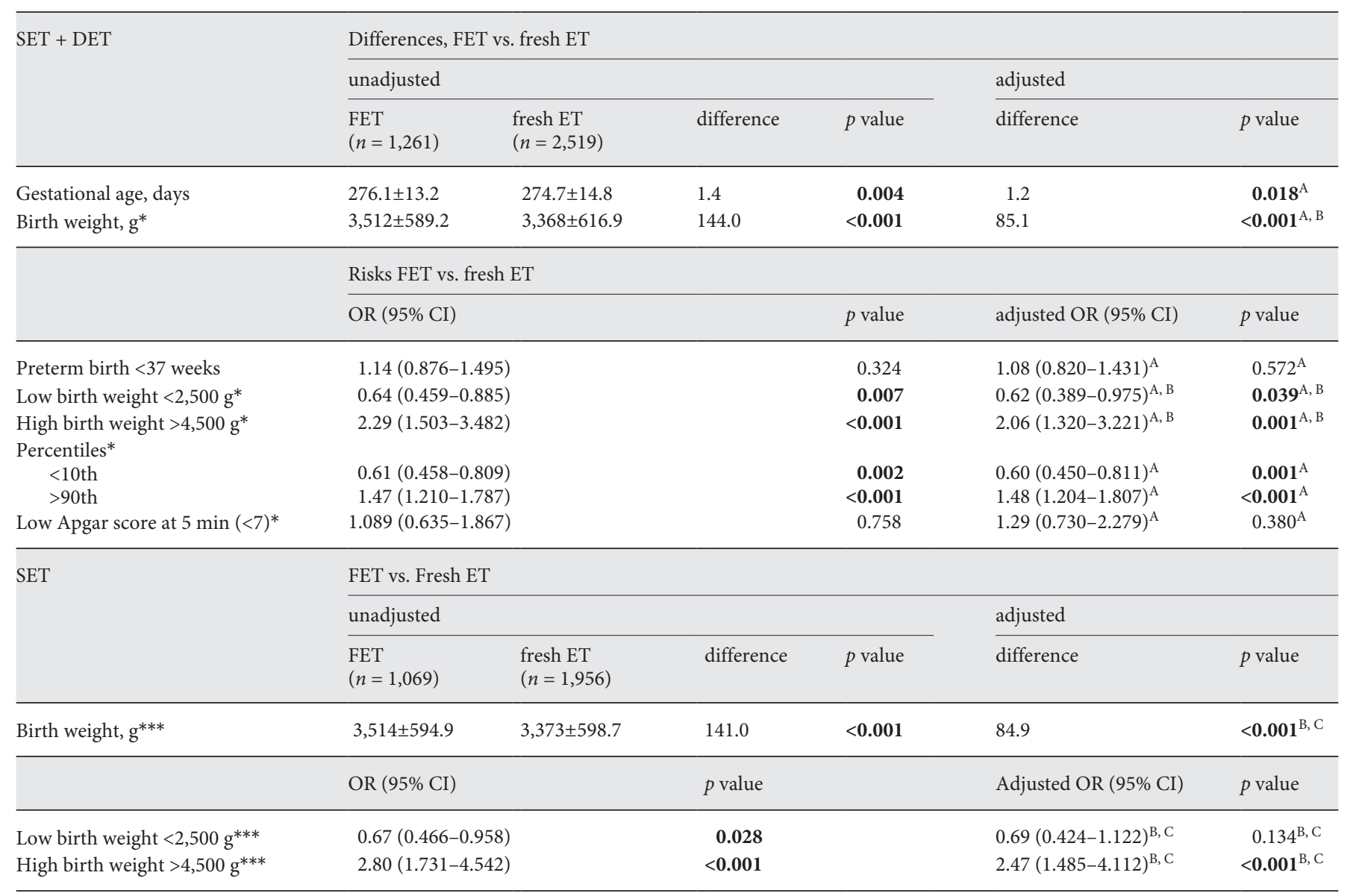

FET, frozen embryo transfer; fresh ET, fresh embryo transfer. * Except unknown values (birth weight: 0.4\%, percentiles: 6.1\%, Apgar score: $36.1 \%$ ). ${ }^{* *}$ Before, during or after birth, after at least 24 weeks of gestation. ${ }^{* * *}$ Except unknown values (5.9\%). ${ }^{A}$ Adjusted for: maternal age, parity, gender of the child and number of embryos transferred. ${ }^{\mathrm{B}}$ Adjusted for gestational age. ${ }^{\mathrm{C}}$ Adjusted for: maternal age, parity and gender of the child. Bold values represent significant results $(p<$ $0.05)$.

(AOR 1.48; 1.204-1.807; $p \leq 0.001)$ compared to fresh ET as well. These results are visualized in online supplemental Figure 1 (see www.karger.com/doi/10.1159/000468935), where a rightward shift can be seen for the FET group. No significant difference in risk of low Apgar score at 5 min $(<7)$ was seen between the frozen-thawed and the fresh ET group.

\section{Comparing FET and Fresh ET with \\ Natural Conception}

To compare FET with natural conception and fresh ET with natural conception, we performed a one-to-one propensity score matching. For this, we only included children born at the VU University Medical Center, which gave a total of 157 children born after transfer of cryopreserved embryos and 423 children born after fresh ET matched with respectively 157 embryos and 423 embryos from the reference group (natural conception). These results are displayed in Table 3. When comparing gestational age between the FET group and the reference group, no significant difference was found. This comparison was also not significant when comparing fresh ET with the reference group. The frozenthawed group showed a significant higher mean birth weight of $192 \mathrm{~g}$ compared to the reference group (3,443 \pm $727 \mathrm{~g}$ for the FET group, 3,251 $\pm 797 \mathrm{~g}$ for the reference group, $\mathrm{p}=0.003)$. The fresh ET group did not show a significant difference in the mean birth weight compared to the reference group when performing a propensity score matching $(3,220 \pm 719 \mathrm{~g}$ for the fresh ET group, 3,263 $\pm 774 \mathrm{~g}$ for the natural conception group, $p=0.402)$. 
Table 3. FET and fresh ET compared to natural conception (propensity score matched)

\begin{tabular}{|c|c|c|c|c|c|c|c|c|}
\hline $\begin{array}{l}\text { Differences } \\
\text { (propensity } \\
\text { score matched) }\end{array}$ & \multicolumn{4}{|c|}{ FET vs. natural conception } & \multicolumn{4}{|c|}{ Fresh ET vs. natural conception } \\
\hline Gestational age, days & $273.8 \pm 17.8$ & $274.9 \pm 20.4$ & 1.1 & 0.629 & $271.2 \pm 19.0$ & $271.3 \pm 22.6$ & 0.1 & 0.908 \\
\hline Birth weight, $\mathrm{g}^{*}$ & $3,443 \pm 727.9$ & $3,251 \pm 796.8$ & 192 & 0.003 & $3,220 \pm 718.7$ & $3,263 \pm 774.1$ & 43 & 0.402 \\
\hline
\end{tabular}

FET, frozen embryo transfer; fresh ET, fresh embryo transfer. * No missing values. Bold values represent significant results $(p<0.05)$.

\section{Additional Analysis}

Because the use of single embryo transfer is increasing compared to the use of DET, we performed an additional analysis to compare the transfer of cryopreserved embryos with fresh ET including only the single embryo transfers (Table 2). We found a significant difference $(p<$ 0.001 ) in birth weight between FET and fresh ET. The risk of LBW $(<2,500 \mathrm{~g})$ in the fresh ET group was significantly higher compared to the FET group $(p=0.028)$. After adjustment, this difference did not remain significant $(p=0.134)$. The risk of a birth weight above $4,500 \mathrm{~g}$ was significantly higher $(p<0.001)$ in the frozen-thawed group compared to that of the fresh group (AOR 2.47; 1.485-4.112).

Within the FET group, both cleavage and blastocyst stage embryo transfer were performed. Additional analysis to compare both groups showed no significant difference in birth weight between cleavage-stage embryo transfer $(3,517 \pm 631 \mathrm{~g})$ and blastocyst stage embryo transfer $(3,503 \pm 581 \mathrm{~g}, p=0.752)$.

\section{Discussion}

This retrospective study included 3,780 children conceived through ART (IVF/ICSI, fresh and FET) and showed that singletons from cryopreservation cycles had a significantly higher birth weight compared to singletons born after fresh cycles, both before and after adjusting for confounding factors. These results correspond to earlier published studies, where an increased risk in high birth weight was also seen in the frozen-thawed embryo transfer group compared to fresh ET group [23-29]. Results also showed that singletons from the FET group have an increased risk of high birth weight $(>4,500 \mathrm{~g})$ and being LGA ( $>90$ th percentile) as well as a decreased risk of LBW $(<2,500 \mathrm{~g})$ and being SGA (below 10th percentile). This can be summarized as a negative skewness in birth weights of the FET group compared to the fresh ET group as is clearly visible in online supplemental Figure 1 and Table 2. Since we included both SET and DET in our research group, we performed an additional analysis where we included only SET in the comparison between FET and fresh ET, as SET is increasingly more common. In this analysis, we found a similar result compared to the original analysis, with significant higher birth weight and more children above 4,500 g in the FET group compared to the fresh ET group. Since we did not find differences in birth weight between cleavage-stage and blastocyststage embryo transfer within the FET group, we assume that the weight difference we found between fresh ET and FET could be contributing to the freezing process.

The difference in gestational age without adjusting for confounders was 1.4 days (adjusted 1.2 days) and this does not explain the observed difference in birth weight (both adjusted and unadjusted). We consider the cryopreservation technique a possible cause of the higher birth weight, since the embryos grow one day extra in vitro after thawing to compensate for the loss of cells in the freezing and thawing processes (embryo transfer takes place day 6 days after HCG injection in the cryopreserved group and after 5 days in the fresh group). As a result, a greater influence of epigenetic factors in culture medium may potentially be responsible for the weight differences found [13].

A recent review showed a slightly favorable cryosurvival and clinical pregnancy rate for vitrification instead of slow-freezing as cryopreservation technique for embryos [37]. We solely use slow-freezing in our center, so this has no implication on our findings. However, different cryopreservation techniques might influence perinatal outcome and more research on this topic might be of great value, since little is yet known about children born after vitrification of embryos versus slow-freezing.

Strengths of this study are both the size of the study as well as the timespan of the collected data. We were able to use nearly 10 years of patient data, during which time there were hardly any changes in the standardized labora- 
tory protocols, besides a change of culture medium in 2009 , which was shown to have no effect on perinatal outcome [35]. However, we were not able to adjust for socioeconomic factors and lifestyle components (e.g., use of alcohol, drugs and nicotine, maternal body mass index [BMI]) due to incomplete data. We acknowledge that these factors might be of great importance for the perinatal outcome of children born after ART as described in other studies [7, 11, 13, 38].

One further question we aimed to answer was how babies born after cryopreservation compared, not only to the fresh ET group, but as well to the naturally conceived population (control group). Using propensity score matching, the fresh ET group did not differ significantly from the reference group in gestational age and mean birth weight. In contrary the FET group did show significant difference in mean birth weight (192 g) when compared to the control group. This indicates that our fresh ET group resembles the control group much more than the cryopreserved group. We acknowledge that our reference group is a limitation of this study because of the medicalized population; however, for the comparison of children born after FET/fresh ET and naturally conceived children, we only used children born at the VU University Medical Center. We also used a propensity score matching to achieve a lower bias between the study population and the control group and therefore obtained a better comparison between these groups.

Besides our own control group, we compared our results to data from other sources. The "Statistics Netherlands" (CBS) data collects information on all children born in the Netherlands. Between 2011 and 2013, according to their data, the mean birth weight of all live born infants was 3,431 $\mathrm{g}$ [39]. Compared to our data we find that the babies born after fresh ET have a lower mean birth weight than the general population, where the children born after cryopreservation have a higher mean birth weight. Compared to results from a recent study where data from the Dutch perinatal birth registration was used [11], we see the same trend. This might indicate, in contrast to what others have found [40], that fresh ET results in a lower birth weight compared to the general population and that cryopreservation leads to a higher birth weight than the general population.

The question remains what the clinical implications of these findings are. Other studies conclude that perinatal outcomes of children born after cryopreservation are even favorable over children born from fresh cycles based on the higher birth weights of children born after FET $[23,24]$. We found no differences in Apgar scores be- tween all groups including the reference group. This implies that the babies had a comparable start irrespective of the way they were conceived and none of them is favorable over the others. Early gestation appears to be of importance for long-term health, as was shown in the Dutch Famine study, early gestational exposure to stress appeared to adverse health outcomes later in life (e.g., coronary heart diseases, obesity and increased stress responsiveness) [41]. Culturing embryos in vitro might have a comparable impact on the long-term health of these children. Since cryopreservation contains a longer culturing phase compared to fresh ET, monitoring effects of this treatment are of great importance in the long term.

It is not clear yet what causes the increased risk of being LGA in children born after cryopreservation. The difference of $144 \mathrm{~g}$ in mean birth weight between frozen-thawed and fresh ET may be small and therefore clinically nonrelevant. The increased risk of being LGA and high birth weight, however, is of clinical importance. It has been shown that children that are LGA have an increased risk for caesarian section, metabolic disturbances, stillbirth, trauma, distress and asphyxia at birth [42-44]. There are studies that suggest epigenetic causes for the increased risk of being LGA in the FET group based on ART in animals [45]. It has been shown that the large offspring syndrome in cattle occurs significantly more often after IVF/ART procedures [46]. Others have shown that this syndrome is genetically similar to the Beckwith-Wiedemann's syndrome in humans, which is indeed epigenetic [47]. In recent research, it was shown that BMI is an independent risk factor for being LGA; however, the investigators were unable to show a connection between BMI and transfer of cryopreserved embryos and therefore conclude that FET is also an independent risk factor for being LGA [48]. Other possible explanations could be the ART procedures itself, embryo quality or maternal factors $[11,49,50]$. We aim to prolong our study to assess the influence of embryo quality, ART procedures and lifestyle factors. Regardless of the cause of the weight difference that we found, cryopreservation does not seem to lead to a higher risk of adverse perinatal outcome. A freeze-all policy is upcoming with the intention to transfer embryos later in a natural cycle to avoid adverse perinatal outcome $[32,51]$, but caution is recommended since the consequences of our findings are not yet evident.

\section{Disclosure Statement}

The authors declare no conflicts of interest. 


\section{References}

1 Schieve LA, Meikle SF, Ferre C, Peterson HB, Jeng G, Wilcox LS: Low and very low birth weight in infants conceived with use of assisted reproductive technology. N Engl J Med 2002;346:731-737.

2 Helmerhorst FM, Perquin DA, Donker D, Keirse MJ: Perinatal outcome of singletons and twins after assisted conception: a systematic review of controlled studies. BMJ 2004; 328:261.

3 Hansen M, Kurinczuk JJ, Milne E, de Klerk N, Bower C: Assisted reproductive technology and birth defects: a systematic review and meta-analysis. Hum Reprod Update 2013;19: 330-353.

4 McDonald SD, Han Z, Mulla S, Murphy KE, Beyene J, Ohlsson A: Preterm birth and low birth weight among in vitro fertilization singletons: a systematic review and meta-analyses. Eur J Obstet Gynecol Reprod Biol 2009; 146:138-148.

5 Jackson RA, Gibson KA, Wu YW, Croughan MS: Perinatal outcomes in singletons following in vitro fertilization: a meta-analysis. $\mathrm{Ob}$ stet Gynecol 2004;103:551-563.

6 Pandey S, Shetty A, Hamilton M, Bhattacharya S, Maheshwari A: Obstetric and perinatal outcomes in singleton pregnancies resulting from IVF/ICSI: a systematic review and metaanalysis. Hum Reprod Update 2012;18:485503.

7 Cooper AR, O’Neill KE, Allsworth JE, Jungheim ES, Odibo AO, Gray DL, et al: Smaller fetal size in singletons after infertility therapies: the influence of technology and the underlying infertility. Fertil Steril 2011;96:1100 1106.

8 Henningsen AK, Pinborg A, Lidegaard $\varnothing$, Vestergaard C, Forman JL, Andersen AN: Perinatal outcome of singleton siblings born after assisted reproductive technology and spontaneous conception: Danish national sibling-cohort study. Fertil Steril 2011;95: 959-963.

9 De Geyter C, De Geyter M, Steimann S, Zhang $\mathrm{H}$, Holzgreve W: Comparative birth weights of singletons born after assisted reproduction and natural conception in previously infertile women. Hum Reprod 2006;21:705-712.

10 De Neubourg D, Gerris J, Mangelschots K, Van Royen E, Vercruyssen M, Steylemans A, et al: The obstetrical and neonatal outcome of babies born after single-embryo transfer in IVF/ICSI compares favourably to spontaneously conceived babies. Hum Reprod 2006; 21:1041-1046.

11 Seggers J, Pontesilli M, Ravelli AC, Painter RC, Hadders-Algra M, Heineman MJ, Repping S, Mol BW, Roseboom TJ, Ensing S: Effects of in vitro fertilization and maternal characteristics on perinatal outcomes: a population-based study using siblings. Fertil Steril 2015;105;590-598.

12 Fujii M, Matsuoka R, Bergel E, van der Poel S, Okai T: Perinatal risk in singleton pregnan- cies after in vitro fertilization. Fertil Steril 2010;94:2113-2117.

13 Pinborg A, Wennerholm UB, Romundstad LB, Loft A, Aittomaki K, Söderström-Anttila $\mathrm{V}$, et al: Why do singletons conceived after assisted reproduction technology have adverse perinatal outcome? Systematic review and meta-analysis. Hum Reprod Update 2012;19: 87-104.

14 Ceelen M, van Weissenbruch MM, Prein J, Smit JJ, Vermeiden JP, Spreeuwenberg M, et al: Growth during infancy and early childhood in relation to blood pressure and body fat measures at age $8-18$ years of IVF children and spontaneously conceived controls born to subfertile parents. Hum Reprod 2009;24: 2788-2795.

15 Ceelen M, van Weissenbruch MM, Roos JC, Vermeiden JP, van Leeuwen FE, Delemarrevan de Waal HA: Body composition in children and adolescents born after in vitro fertilization or spontaneous conception. J Clin Endocrinol Metab 2007;92:3417-3423.

16 Pontesilli M, Painter RC, Grooten IJ, van der Post JA, Mol BW, Vrijkotte TG, et al: Subfertility and assisted reproduction techniques are associated with poorer cardiometabolic profiles in childhood. Reprod Biomed Online 2015;30:258-267.

17 Hart R, Norman RJ: The longer-term health outcomes for children born as a result of IVF treatment: part I - general health outcomes. Hum Reprod Update 2013;19:232-243.

18 Zeilmaker GH, Alberda AT, van Gent I, Rijkmans CM, Drogendijk AC: Two pregnancies following transfer of intact frozen-thawed embryos. Fertil Steril 1984;42:293-296.

19 Sullivan EA, Zegers-Hochschild F, Mansour $\mathrm{R}$, Ishihara $\mathrm{O}$, de Mouzon J, Nygren KG, et al: International Committee for Monitoring Assisted Reproductive Technologies (ICMART) world report: assisted reproductive technology 2004. Hum Reprod 2013;28:1375-1390.

20 Roque M, Lattes K, Serra S, Solà I, Geber S, Carreras R, et al: Fresh embryo transfer versus frozen embryo transfer in in vitro fertilization cycles: a systematic review and meta-analysis. Fertil Steril 2013;99:156-62.

21 Thurin A, Hausken J, Hillensjö T, Jablonowska B, Pinborg A, Strandell A, et al: Elective single-embryo transfer versus double-embryo transfer in in vitro fertilization. $\mathrm{N}$ Engl J Med 2004;351:2392-2402.

22 Gerris J, De Neubourg D, Mangelschots K, Van Royen E, Vercruyssen M, BarudyVasquez J, et al: Elective single day 3 embryo transfer halves the twinning rate without decrease in the ongoing pregnancy rate of an IVF/ICSI programme. Hum Reprod 2002;17: 2626-2631.

23 Pinborg A, Loft A, Aaris Henningsen AK, Rasmussen S, Andersen AN: Infant outcome of 957 singletons born after frozen embryo replacement: the Danish National Cohort Study 1995-2006. Fertil Steril 2010;94:1320-1327.
24 Pelkonen S, Koivunen R, Gissler M, NuojuaHuttunen S, Suikkari AM, Hydén-Granskog C, et al: Perinatal outcome of children born after frozen and fresh embryo transfer: the Finnish cohort study 1995-2006. Hum Reprod 2010;25:914-923.

$25 \mathrm{Li} \mathrm{Z}$, Wang YA, Ledger W, Edgar DH, Sullivan EA: Clinical outcomes following cryopreservation of blastocysts by vitrification or slow freezing: a population-based cohort study. Hum Reprod 2014;29:27942801.

26 Wennerholm UB, Henningsen AK, Romundstad LB, Bergh C, Pinborg A, Skjaerven $R$, et al: Perinatal outcomes of children born after frozen-thawed embryo transfer: a Nordic cohort study from the CoNARTaS group. Hum Reprod 2013;28: 2545-2553.

27 Wikland M, Hardarson T, Hillensjö T, Westin C, Westlander G, Wood M, et al: Obstetric outcomes after transfer of vitrified blastocysts. Hum Reprod 2010;25:1699-1707.

28 Maheshwari A, Pandey S, Shetty A, Hamilton M, Bhattacharya S: Obstetric and perinatal outcomes in singleton pregnancies resulting from the transfer of frozen thawed versus fresh embryos generated through in vitro fertilization treatment: a systematic review and meta-analysis. Fertil Steril 2012;98:368-377. e1-e9.

29 Sazonova A, Källen K, Thurin-Kjellberg A, Wennerholm UB, Bergh C: Obstetric outcome in singletons after in vitro fertilization with cryopreserved/thawed embryos. Hum Reprod 2012;27:1343-1350.

30 Pelkonen S, Hartikainen AL, Ritvanen A, Koivunen R, Martikainen H, Gissler M, et al: Major congenital anomalies in children born after frozen embryo transfer: a cohort study 1995-2006. Hum Reprod 2014;29:15521557.

31 Belva F, Henriet S, Van den Abbeel E, Camus M, Devroey P, Van der Elst J, et al: Neonatal outcome of 937 children born after transfer of cryopreserved embryos obtained by ICSI and IVF and comparison with outcome data of fresh ICSI and IVF cycles. Hum Reprod 2008; 23:2227-2238

32 Roque M, Valle M, Guimarães F, Sampaio M, Geber S: Freeze-all policy: fresh vs. frozenthawed embryo transfer. Fertil Steril 2015; 103:1190-1193.

33 NVOG: Richtlijn Perinataal Beleid bij Extreme Vroeggeboorte, 2010.

34 Pinborg A, Lidegaard O, Freiesleben Nl, Andersen AN: Vanishing twins: a predictor of small-for-gestational age in IVF singletons. Hum Reprod 2007;22:2707-2714.

35 Vergouw CG, Kostelijk EH, Doejaaren E, Hompes PG, Lambalk CB, Schats R: The influence of the type of embryo culture medium on neonatal birthweight after single embryo transfer in IVF. Hum Reprod 2012;27:26192626. 
36 Vergouw CG, Botros LL, Judge K, Henson M, Roos P, Kostelijk EH, et al: Non-invasive viability assessment of day- 4 frozen-thawed human embryos using near infrared spectroscopy. Reprod Biomed Online 2011;23:769776.

37 Rienzi L, Gracia C, Maggiulli R, LaBarbera AR, Kaser DJ, Ubaldi FM, et al: Oocyte, embryo and blastocyst cryopreservation in ART: systematic review and meta-analysis comparing slow-freezing versus vitrification to produce evidence for the development of global guidance. Hum Reprod Update 2017;23:139155.

38 Sazonova A, Källen $\mathrm{K}$, Thurin-Kjellberg A, Wennerholm UB, Bergh C: Factors affecting obstetric outcome of singletons born after IVF. Hum Reprod 2011;26:2878-2886.

39 Central Bureau voor de Statistiek: Bevalling en geboorte: 1989-2013. 2015. http://statline.cbs. $\mathrm{nl} /$ Statweb/publication/?DM=SLNL\&PA=37 $302 \& \mathrm{D} 1=23-44 \& \mathrm{D} 2=0 \& \mathrm{D} 3=0,3,8,1 \& \mathrm{VW}=\mathrm{T}]$.

40 Sazonova A, Källen K, Thurin-Kjellberg A Wennerholm UB, Bergh C: Obstetric outcome after in vitro fertilization with single or double embryo transfer. Hum Reprod 2011; 26:442-450.

41 Roseboom T, de Rooij S, Painter R: The Dutch famine and its long-term consequences for adult health. Early Hum Dev 2006;82:485491.

42 Henriksen T: The macrosomic fetus: a challenge in current obstetrics. Acta Obstet Gynecol Scand 2008;87:134-145.

43 Bukowski R, Hansen NI, Willinger M, Reddy UM, Parker CB, Pinar H, et al: Fetal growth and risk of stillbirth: a population-based casecontrol study. PLoS Med 2014;11:e1001633.

44 Weissmann-Brenner A, Simchen MJ, Zilberberg E, Kalter A, Weisz B, Achiron R, et al: Maternal and neonatal outcomes of large for gestational age pregnancies. Acta Obstet Gynecol Scand 2012;91:844-849.

45 Grace KS, Sinclair KD: Assisted reproductive technology, epigenetics, and long-term health: a developmental time bomb still ticking. Semin Reprod Med 2009;27:409-416.

46 Young LE, Sinclair KD, Wilmut I: Large offspring syndrome in cattle and sheep. Rev Reprod 1998;3:155-163.
47 Chen Z, Robbins KM, Wells KD, Rivera RM: Large offspring syndrome: a bovine model for the human loss-of-imprinting overgrowth syndrome Beckwith-Wiedemann. Epigenetics 2013;8:591-601.

48 Korosec S, Frangez HB, Steblovnik L, Verdenik I, Bokal EV: Independent factors influencing large-for-gestation birth weight in singletons born after in vitro fertilization. J Assist Reprod Genet 2016;33:9-17.

49 Pinborg A, Henningsen AA, Loft A, Malchau SS, Forman J, Andersen AN: Large baby syndrome in singletons born after frozen embryo transfer (FET): is it due to maternal factors or the cryotechnique? Hum Reprod 2014;29: 618-627.

50 Maas K, Galkina E, Thornton K, Penzias AS, Sakkas D: No change in live birthweight of IVF singleton deliveries over an 18-year period despite significant clinical and laboratory changes. Hum Reprod 2016;31:1987-1996.

51 Weinerman R, Mainigi M: Why we should transfer frozen instead of fresh embryos: the translational rationale. Fertil Steril 2014;102: $10-18$. 